\title{
Sostenibilidad de los grupos de danza folclórica independientes y universitarios de la ciudad de Medellín*
}

\author{
Lina Marcela Silva Ramírez \\ Universidad de Antioquia, Medellín, Colombia \\ lina.silva@udea.edu.co \\ https://orcid.org/0000-0002-7494-3488
}

\section{RESUMEN}

La sostenibilidad es uno de los temas más críticos para el sector cultural colombiano, no solo por la complejidad derivada de la naturaleza del producto creativo, sino por las condiciones de posibilidad en las cuales se ejercen las diferentes expresiones artísticas. Los retos en el marco de la economía naranja son numerosos, además de las necesidades no resueltas en cuanto a la participación y la organización de los colectivos para establecerse productivamente. Este ensayo se centra en la revisión de este tema desde un enfoque integral, particularmente en el caso de los grupos de danza folclórica colombiana que ejercen su práctica en Medellín, con el fin de establecer un panorama actual del subsector de danza y motivar el fortalecimiento de la planeación de sus procesos de gestión en torno a la financiación. Asimismo, apunta a la construcción de entornos políticos favorables y solidarios en los que se tengan en cuenta las necesidades reales de los colectivos y unas estrategias consolidadas mediante las cuales sea posible una mayor incidencia en las agendas culturales de la región.

Palabras clave: sostenibilidad integral; danza folclórica colombiana; políticas culturales; gestión cultural.

Cómo citar: Silva Ramírez, L. M. (2019). Sostenibilidad de los grupos de danza folclórica independientes y universitarios de la ciudad de Medellín. Ciencias Sociales y Educación, 8(15), 177-202. DOI: https://doi.org/10.22395/ csye.v8n15a9

Recibido: 5 de abril de 2019.

Aprobado: 13 de junio de 2019. 


\section{Sustainability of the Independent and University Folklore Dancing Groups in the City of Medellín}

\section{ABSTRACT}

Sustainability is one of the most critical topics for the Colombian cultural sector, not only because of the complexity derived from the nature of the creative products but also for the conditions of possibility in which the different artistic expressions are exercised. The challenges in the orange economy framework are numerous, as well as the unresolved needs in matters of participation and organization by collectives for establishing themselves productively. This essay focuses on the review of this topic from an integral perspective, parti- cularly in the case of the folkloric dance groups that exercise their art in Medellin, intending to establish an actual panorama of their management processes in terms of financing. Likewise, it points toward the building of favorable and solidary political surroundings with the real needs of the collectives in mind and some consolidated strategies with which a greater impact on the regional cultural agendas are possible.

Keywords: integral sustainability; Colombian folkloric dance; cultural policies; cultural management.

\section{Sustentabilidade dos grupos de dança folclórica independentes e universitários da cidade de Medellín}

\section{RESUMO}

A sustentabilidade é um dos temas mais críticos para o setor cultural colombiano não somente pela complexidade derivada da natureza do produto criativo, mas também pelas condições de possibilidade nas quais são exercidas as diferentes expressões artísticas. Os desafios no âmbito da economia laranja são numerosos, além das necessidades não resolvidas quanto à participação e organização dos grupos para que se consolidem produtivamente. Este ensaio está centralizado na revisão desse tema a partir de uma abordagem integral do caso dos grupos de dança folclórica colombiana que exercem sua prática em Medellín, a fim de estabelecer um panorama atual do subsetor de dança e motivar o fortalecimento do planejamento de seus processos de gestão em torno do financiamento. Ainda, aponta a construção de contextos políticos favoráveis e solidários em que as necessidades reais dos coletivos e as estratégias consolidadas sejam consideradas e possam incidir nas agendas culturais da região.

Palavras-chave: sustentabilidade integral; dança folclórica colombiana; políticas culturais; gestão cultural. 


\section{Introducción}

Uno de los retos más significativos para los grupos artísticos en la ciudad de Medellín es la sostenibilidad, entendida como un proceso integral en el cual intervienen varios factores de orden económico y político y que al parecer contiene en sí mismo una variedad de contradicciones.

El primer elemento que se debe abordar al respecto es el tema de las diferentes concepciones que tienen los actores sociales sobre el tema de la sostenibilidad. A pesar de que en la mayoría de los casos esta suele asociarse con aspectos financieros, la realidad evidencia que para los grupos independientes de danza la permanencia en el tiempo está ligada a procesos de voluntariado de sus integrantes, bajas remuneraciones, poco reconocimiento del trabajo de los directores y una competencia constante derivada de las políticas locales para la distribución de los recursos destinados a la cultura.

Para dar luces sobre esta problemática se abordó a los representantes de los grupos que integran la Red Independiente Arcalía, la Red de Danza Folclórica de Medellín y el valle de Aburrá, que busca generar espacios de integración, intercambio y construcción de saberes que permitan fortalecer los procesos de la danza folclórica para incidir en las políticas culturales del sector. Durante la investigación, se definió como objetivo central comprender las dinámicas de sostenibilidad de los grupos de danza folclórica y las garantías existentes en Medellín para el ejercicio de la danza desde un enfoque crítico. Cada uno de los ejes del ensayo corresponde al objetivo específico formulado para la reflexión, centrada en tres cuestiones: ¿Qué características y condiciones de posibilidad ha tenido la sostenibilidad en el sector de la danza folclórica en la voz de sus actores? ¿Cuáles son los procesos, estrategias y aportes de las políticas culturales locales y su impacto en la sostenibilidad de los grupos de danza folclórica de la ciudad?

\section{¿Qué implica hablar de sostenibilidad de los grupos de danza folclórica independientes y univer- sitarios?}

El principal factor de motivación para la indagación y escritura de este ensayo se dio en oposición a una de las afirmaciones contenidas en el "Estado del arte de los grupos independientes y universitarios de danza folclórica de Medellín", realizado por la Corporación Vía Libre y la red Arcalía del sector de danza folclórica de Medellín y el Valle de Aburrá en 2016. En éste se indicaba que la sostenibilidad era un componente poco explorado. Ante esta visión y los escasos datos que la soportaban, se eligió profundizar en aquello que se entiende como dinámicas de la sostenibilidad, los posibles enfoques desde los cuales se aborda y sus características para el caso de los grupos de danza, ya fueran constituidos legalmente o no, pero que realizaran su trabajo de manera independiente. 
Uno de los hallazgos del estado del arte mencionado fue la medición de las actividades realizadas sin mayor estructuración dentro del componente de sostenibilidad y que pueden llegar a ser relevantes cuando se aborda el tema desde un enfoque crítico. Para este momento se presentaron las siguientes cifras:

El 39 \% de las entidades realizan procesos de formación a formadores en perspectiva de relevo o intercambio generacional, esto es un porcentaje bajo teniendo en cuenta que es a través de este medio que se puede garantizar la trascendencia del trabajo en el tiempo y en otras generaciones.

El 94 \% realizan planeación de sus procesos, esto implica una visión más organizada del hacer que potencia los mismos. El $85 \%$ de las entidades realizan alianzas con pares del sector cultural y otros sectores para el desarrollo de sus acciones, ampliando su fuerza en la suma con otros. El $52 \%$ de las entidades integran al menos una red relacionada con la investigación, formación, creación o proyección, y de ellas solo Fantasía Guayaquil y la Corporación Cultural Canchimalos hacen parte de 3 redes, esto es vital para aunar esfuerzos en propósitos comunes.

El $64 \%$ de entidades hace parte de instancias de participación ciudadana como consejos de cultura, comisiones de cultura, mesas de cultura, comités barriales o Juntas de Acción Comunal entre otros, haciendo más visible y participativa en el territorio o el gremio su labor. De las entidades caracterizadas, solo Djembé no realiza acciones como las descritas en relación con la sostenibilidad. (Arcalía, 2016, p. 50)

Como es evidente, la sostenibilidad no contaba con un lugar central en los procesos de los grupos, a pesar de ser una problemática que afecta a todos y de que, en la práctica, se realizan constantes esfuerzos para alcanzar la permanencia en el tiempo. Estas cifras también permitieron observar el poco interés de las entidades y organizaciones en los procesos formativos que parecen ser una estrategia desgastada entre el subsector, toda vez que la experiencia ha demostrado que el conocimiento no implica estabilidad de los procesos.

Por otra parte, los datos también permitieron identificar que los grupos habían empezado a reconocer la importancia de la planeación estratégica como un paso hacia el fortalecimiento de sus proyectos, así como de las alianzas y el trabajo en red para dinamizar sus acciones. Sin embargo, hoy en día la participación sigue siendo un talón de Aquiles ya que los grupos parecen no verse reflejados en la construcción de ciudadanía.

En este trabajo también se identificó la configuración de diversas formas de entender la sostenibilidad. Llama la atención la referencia a la "sostenibilidad integral" propuesta por Castrillón (2015), en donde se destaca un salto del enfoque economicista a una mirada más política en la cual se incluye:

[...] mejorar los niveles de participación de las comunidades (como ciudadanos, sujetos y beneficiarios); la posibilidad de circulación e intercambio a nivel local, nacional e internacional (que permita la retroalimentación permanente y la generación 
de lazos); la presencia de generaciones de relevo (en las niñas, niños, adolescentes y jóvenes, que amen la cultura y amen las comunidades), procesos de planificación (que ayuden a definir con claridad los caminos a seguir hacia el futuro), y estrategias de investigación y formación de los agentes responsables de las organizaciones (que les dé conocimientos y claridad conceptual). (p. 2)

Después de tener un acercamiento a la realidad de los grupos de danza folclórica independientes y universitarios de la ciudad de Medellín se reconoció también que cuando se desarrollan procesos de danza folclórica se incluyen aspectos comunitarios, simbólicos, estéticos, sabiduría ancestral, conocimiento, sensibilidad, y creatividad. En la danza folclórica existen las bases de nuestras tradiciones, historia, memoria, identidad y patrimonio.

Si se reconoce que la mayoría de los grupos cuentan con factores similares en su permanencia, podría afirmarse, por ejemplo, que buena parte de su trabajo artístico se apoya en el intercambio social como el voluntariado, los favores (trueque), el establecimiento de alianzas y el fortalecimiento de relaciones basadas en las necesidades compartidas.

Es claro entonces que este contexto oculto de los grupos de danza no es visible para la sociedad, pues el "hacer" se reduce generalmente a una función en el escenario. Pero detrás del escenario hay un "ser" que, aunque en la mayoría de los casos hace un trabajo silencioso y voluntario, se soporta en el amor y la pasión hacia la danza folclórica que incluye ensayos, estudio, investigación, alianzas, trabajo con pares, gestión cultural... En medio de tantas líneas estratégicas como la investigación, la formación, la proyección y circulación de los grupos, es la sostenibilidad la que transversaliza ese "hacer" y "ser" de los grupos de danza.

La sostenibilidad integral se convierte en el soporte que les permite permanecer y soñar con un futuro digno que incluya lo social, el bienestar, las estrategias de protección, la salud y la atención a los integrantes de los grupos desde una mirada integral, no solo en la búsqueda de rentabilidad económica, sino también social y cultural.

De acuerdo con el principal antecedente del ensayo propuesto, aún no se alcanza a vislumbrar un elemento que es fundamental para abordar el aspecto de la sostenibilidad integral. Este aspecto consiste precisamente en identificar qué lugar ocupan instancias como el Estado y las entidades de carácter privado, ya que se distingue claramente cómo la sostenibilidad de los grupos de danza folclórica de Medellín están bajo la responsabilidad directa de los mismos agentes de la danza: directores, bailarines, docentes, administrativos y todo el equipo de apoyo que poseen los grupos donde en la mayoría de los casos no reciben ninguna remuneración, sino que es una labor realizada de 
forma voluntaria y durante largos periodos de tiempo. Es por esta razón que el presente ensayo quiso abordar las voces de estos actores, algunos de ellos con una amplia trayectoria en el sector, que han vivenciado las variaciones ocurridas desde los albores de sus proyectos culturales. Y dado que muchos de ellos se han mantenido gracias al cobijo de las universidades, estos también fueron convocados, aunque es pertinente anotar que la sostenibilidad mediada por la institucionalidad adquiere perspectivas y formas de trabajo diferentes.

Una vez se establece el punto de debate anteriormente descrito, surge una arriesgada hipótesis que considera la existencia de un funcionamiento independiente de los grupos de danza folclórica que puede contener una base de lo que se ha denominado en las teorías de la cultura libre: los bienes comunes, es decir, "la gestión y propiedad colectiva de recursos productivos" (Rowan, 2016, p. 18). En el caso de la danza folclórica en la ciudad corresponde al capital social existente tras el espectáculo y que posibilita que las cosas se den a pesar de las dificultades e inexistencia de recursos económicos. En otras palabras, este ensayo propone la presencia de elementos que podrían favorecer la gestión de recursos productivos en clave de colectividad, desde la fuerza social que los convoca y no únicamente desde el punto de vista economicista que reduce significativamente el campo de acción y operaciones de la sostenibilidad en entornos culturales.

\section{El enfoque crítico de la sostenibilidad}

El lugar de enunciación desde el cual se aborda la realidad planteada es el de una bailarina que también es formada en artes escénicas, en sociología y en historia. A lo largo de sus experiencias creativas y profesionales ha observado y experimentado las dificultades de "hacer" arte en la ciudad. Sumado a lo anterior, la cercanía con los procesos de planeación cultural a nivel local también nutrió la pregunta por las complejidades que afrontan los grupos para mantenerse, responder a un nivel artístico y gestionar los recursos necesarios para la proyección.

Desde el punto de vista académico, esta enunciación se orienta a comprender la sostenibilidad como un proceso complejo en el cual converge otros procesos, tales como la formación, la investigación, la creación y la circulación de las obras, sin mencionar los avatares que implica la consecución de espacios de ensayo, almacenamiento, oficinas, indumentaria, publicidad, etc.

Considerar el concepto de sostenibilidad como inmerso en una perspectiva compleja requiere un mínimo distanciamiento de los modelos que pretenden incluirla como un ítem para valorar la solidez de las propuestas y proyectos, lo cual también ha ido implementado paulatinamente la demanda por una 
autogestión de los grupos bajo un modelo de negocios. La invitación es que se valore lo que durante más de dos décadas los actores culturales de la danza han venido consolidando, más allá de la visión progresista que instauran las industrias culturales. Asimismo, es importante que se aprecien los modos en que los actores han permanecido sin comprender o ahondar, en muchos casos, las dinámicas que proponen las políticas culturales.

Es así como, en lugar de las ganancias monetarias, se abordan el espacio y las relaciones sociales que se tejen alrededor de las vivencias de la sostenibilidad. De acuerdo con Anastasopoulos (2017):

La sostenibilidad es un concepto que emerge a finales del siglo $\mathrm{xx}$, el cual indica la capacidad de mantenerse en la existencia sin interrupción o disminución (...) para que esto suceda, cuando una condición cambia las estructuras dependientes deben, en consecuencia, adaptarse para alcanzar un nuevo estado de equilibrio (p. 42).

Se ha visto que los grupos de danza folclórica, como un producto cultural local, han mantenido su ejercicio y lentamente han configurado sus propios espacios de injerencia. Han sido impulsados por la labor de conservación de la memoria iniciada por maestros como Oscar Vahos, Pedro Betancur, Argiro Ochoa, Alberto Londoño y seguida por otras apuestas entre las que se encuentran personajes como Walter Gómez Palacios, Mauricio Aristizabal, William Atehortúa, Javier Álvarez, entre otras personalidades que también tejieron un puente con la academia, al consolidar y mantener vigentes los grupos universitarios con más trayectoria en la ciudad. En cada uno de ellos descansa una labor formativa importante, en tanto se ha transmitido el saber dancístico de manera informal y se han formado nuevos líderes independientes que conforman el mapa actual de agrupaciones.

Una de las características de estos grupos es que su rango de acción no se reduce al ámbito municipal, sino que se relacionan con otros municipios del área metropolitana, participan en procesos y proyectos nacionales y realizan intercambios internacionales. Además, algunos de ellos han logrado conformar semilleros de formación para niños y jóvenes, así como el establecimiento de dos salas de danza en la ciudad.

Lo anterior también lleva a plantear que, entre los términos relevantes para referenciar la sostenibilidad de los grupos de danza folclórica independiente, existen las nociones de:

- Interdependencia: Se relaciona con la consciencia sistémica con la cual se mueven los grupos tanto en su territorio como en los vínculos humanos generados que posibilitan muchas de sus acciones. 
- Formas de agenciamiento: Se entienden como las propuestas y dinámicas generadas por las agrupaciones para responder a las necesidades de su hacer. Este término también cuenta con un carácter político ya que a partir de estas dinámicas también se definen roles, autoridad e interacciones internas y externas. Holismo: Desde esta visión, se propone específicamente considerar que, al observar la sostenibilidad desde otro enfoque más amplio, también se amplían las lecturas posibles de las problemáticas y sus fuentes, los conflictos y contradicciones que pueden existir alrededor de ella.

\section{Características y condiciones de posibilidad de la sostenibilidad en la voz de sus actores}

En este eje de reflexión se busca acudir a la voz de los actores para responder a las siguientes preguntas: ¿Cómo se observa la sostenibilidad de los grupos de danza independientes con relación al paso del tiempo? ¿Cuáles son las acciones más importantes para el tema de sostenibilidad de sus procesos en torno a la danza? Con respecto a la primera cuestión, uno de los maestros más reconocidos mencionó:

En tiempos pasados los grupos se auto sostenían con empanadas, con rifas, con paseos y con aportes personales, cada integrante aportaba una cuota semanal, y con esos dineros financiaban los viajes y el vestuario, generalmente las mamás aportaban mucho con la costura y la confección de los vestidos esto fue fundamentalmente en los años 50 y 60, no había apoyos gubernamentales de ninguna clase, todo se hacía con esfuerzos muy personales. También se hacían veladas, funciones en escuelas o parroquias del barrio y los familiares aportaban comprando las boletas para ir al espectáculo y así ayudar al grupo generalmente cuando este pretendía hacer un viaje a algún festival. (Londoño, comunicación personal, 7 de noviembre de 2018)

De acuerdo con las entrevistas realizadas, en los años 70 inician las primeras intervenciones gubernamentales tendientes a reconocer la danza folclórica como un elemento importante para la planeación. Por tanto, empiezan a incluirla en las agendas culturales de la ciudad y a estimular los llamados "patrocinios" por parte de diversas entidades públicas y privadas:

La mayoría de los grupos fueron patrocinados por empresas y entidades del gobierno, bancos, fábricas y esas empresas financiaban todos los costos del grupo, inclusive algunos le pagaban al director por su trabajo, fue el tiempo dorado, donde muchos grupos adquirieron muy buen vestuario y muy buena calidad en sus propuestas coreográficas, esto duró hasta los años 80 cuando las empresas se quebraron por la crisis textilera y la mayoría retiró los patrocinios a los grupos de danza. (Londoño, comunicación personal, 7 de noviembre de 2018)

De esta manera, se configuraron las dinámicas de apoyo que caracterizaron las décadas de 1980 y 1990 cuando las Secretarías de Cultura y Educación se ocuparon de gestionar programaciones y pagar por presentaciones. Según 
el maestro Alberto Londoño, en esta época también se dio una bonanza por parte de las empresas locales con programas como "Metro Cultura" del Metro de Medellín, que buscaba el fomento de los grupos a través de funciones en las estaciones recién inauguradas. Asimismo, se contó con la participación de Comfama, que llevaba grupos a todos sus parques semanalmente.

Al respecto, Camilo Maldonado también menciona que

existieron en los años 90 los fondos mixtos, pero había menos competencia, menos quién participaran en esas convocatorias, digamos que los pocos que participaban tenían ese apoyo económico (...) grupos que se movían en presentaciones en municipios, que se daba mucho en el pasado. (Maldonado, comunicación personal, 9 de noviembre de 2018)

Con la inserción de estas nuevas formas de "hacer" danza en la ciudad se transita desde una concepción del simple ejercicio de montar un repertorio y presentarlo ante una audiencia hacia la formulación de proyectos estructurados que proponen los artistas con diferentes momentos como la producción, el contenido de la puesta en escena y las disposiciones presupuestales en las cuales fue surgiendo, paulatinamente, el tema de la sostenibilidad. Este tránsito también fue relevante ya que configuró el contexto de las políticas de apoyo gubernamental.

Para Nancy Muñoz, directora del grupo Tejiendo el Azar, estas políticas han favorecido la transformación en las maneras de acceder a recursos, ya que actualmente existen condiciones diferentes, como lo expresa a continuación:

Se ve en el horizonte posibilidades de permanecer un poco más, en la medida en que si hay condiciones los grupos pueden mirar la posibilidad de fortalecerse a nivel económico, aunque no sea mucho. (...) antes, todo tenía que ser de parte de ellos, es decir, con sus acciones cotidianas de vender empanadas, boletas, de hacer temporada, de diversas y miles de acciones que se hacen en los grupos para poder hacer un vestuario, por ejemplo. Digamos que eso se sigue haciendo, pero que entra la posibilidad de pensar, por ejemplo, en una beca de circulación, que van a entrar unos recursos que apoyan esas ideas, o que permiten cristalizar esas ideas que los grupos van desarrollando o van tratando de formalizar, antes de eso, era muy difícil acceder a recursos del estado, ahora creo que han mejorado, se ha permitido que los grupos de pronto tengan mayor tiempo en el escenario artístico y que se sientan fortalecidos, que se debe seguir trabajando para que se mejoren las condiciones, claro que sí, pero sí ha habido unos cambios interesantes e importantes en esas políticas. (Muñoz, comunicación personal, 5 de noviembre de 2018)

La sensación que prevalece en diálogos con los actores entrevistados es similar. Tiene que ver con la presencia de unas políticas que no han logrado responder efectivamente a las necesidades de los grupos y que en muchas ocasiones hacen más dispendioso el trabajo, ya sea por la dinámica de competencia en la 
que se debe ingresar o por la papelería, documentación y trámites que solicitan. Sin embargo, la mayoría coinciden en que las dinámicas de ordenamiento de los recursos como el programa de Estímulos, Presupuesto Participativo y Becas han sido hasta el momento una fuente importante para la financiación y movilidad de los grupos.

Ante la misma pregunta, también existen versiones dentro de los actores entrevistados, en las que se observa una percepción de la sostenibilidad relacionada con los débiles procesos internos de transferencia intergeneracional. Para el presidente del consejo de danza de Medellín, Camilo Maldonado, las razones por las cuales algunos grupos de danza folclórica han desaparecido del panorama local es que los fundadores han muerto sin dejar un legado concreto o sin haber "sembrado semilla" de su trabajo. Con respecto a esto sostiene que "en general, las organizaciones culturales han tenido continuidad (...) en el área metropolitana han surgido otras, de una mediana trayectoria y que también han tenido una continuidad" (Maldonado, comunicación personal, 9 de noviembre de 2018).

De acuerdo con lo observado en estas visiones o voces de algunos de los actores y líderes de los procesos dancísticos de la ciudad, la sostenibilidad actual se encuentra mediada por la intervención estatal y por las formas en las que internamente los grupos agencian su participación, así como por el trabajo que realizan para dar continuidad a sus labores.

\section{Acciones en favor de la sostenibilidad}

En cuanto a la pregunta por las acciones realizadas en aras a fortalecer la sostenibilidad, algunos de los actores cuestionados consideran que una de las grandes debilidades del sector es la oferta de espectáculos y obras, ya que hay poca convocatoria de nuevos públicos porque el folclor se vuelve repetitivo en su ejecución y puesta en escena. En este sentido comenta el maestro Alberto Londoño:

Se hace necesario trabajar en la producción de propuestas novedosas no solo para vender los espectáculos sino fundamentalmente en crearlos y es muy importante hacer una red con grupos semiprofesionales que hagan propuestas de alto nivel y comenzar a vender este tipo de espectáculos para que la gente, el público comience a entender, que la danza folclórica puede ofrecer un espectáculo bastante interesante. (Londoño, comunicación personal, 7 de noviembre de 2018)

En esta perspectiva, coincide Camilo Maldonado cuando afirma que:

[...] tanto en el pasado como en la actualidad, los grupos artísticos no se sostienen a punta de presentaciones, porque también hay un asunto que se mueve por la demanda del folclor que no es muy grande en términos comerciales y otro 
asunto también es la baja calidad del producto artístico que tienen muchas las agrupaciones, porque muchas de ellas ofrecen un trabajo de fines de semana, un trabajo mucho más amateur, y en términos empresariales no se piensa en un producto para un consumo de un espectador, sino para un goce de familias, de cercanos, más para un formato de compartir que para un asunto de vender; sin embargo, muchos de ellos esperan generar una economía con ese tipo de productos; allí se genera una contradicción entre lo que es el resultado final, y la posibilidad de compra de ese tipo de productos artísticos. (Maldonado, comunicación personal, 9 de noviembre de 2018)

De esta manera, se consolida una visión que se conecta con el quehacer de la danza folclórica y las nuevas formas de transmisión de los legados culturales que están ligados a la innovación en el oficio. También existe una posición entre las personas abordadas que va más encaminada a la necesidad de fortalecer la participación y la actualización frente a los debates y temáticas abordadas por las políticas culturales. En este sentido, se plantea que

[...] es fundamental y vital para poder estar ahí en esas posibilidades que brinda el estado ya que este se convierte casi que en el único ente de contratación porque (...) la empresa privada es difícil para este tipo de cosas, pero a la vez también pensamos que si eso no va aunado o correlacionado con una formación en el campo artístico y en el campo de formación dancística y de formación proyectiva, eso tiende a caer, y también, de formación investigativa, es algo de doble vía, y lógicamente la persistencia y la constancia de estar ahí, en la jugada, hace parte fundamental del proceso de sostenibilidad. (Muñoz, comunicación personal, 5 de noviembre de 2018)

En esta misma vía se presentan opiniones relacionadas con una urgente flexibilización y acompañamiento ante las exigencias que se tienen para acceder a la legalización de los grupos frente a instancias como Cámara de Comercio. Tener una figura formal posibilita la apertura de oportunidades y una mayor incidencia de algunas agrupaciones en el medio, el establecimiento de alianzas y relaciones económicas, entre otros elementos potenciadores de la sostenibilidad.

Finalmente, otras perspectivas tienen que ver con el fortalecimiento de los procesos de planeación que tienen los grupos encaminados a mejorar sus gestiones, proyecciones y "deber ser" como entidades culturales. En este contexto se considera importante generar planes de trabajo, comerciales y ejecutar objetivos de acuerdo con la naturaleza de cada uno de los grupos, puesto que se reconoce que las dinámicas son diferentes en una agrupación cuya fortaleza es la formación, otra que centre su acción en la generación de un producto artístico llamativo y otra que se oriente a proyectar su trabajo hacia las comunidades o el sentido social.

Sin embargo, las condiciones de posibilidad actuales de los grupos no se agotan en este punto, por lo que conviene considerar las dinámicas económicas y creativas en las cuales está envuelto el subsector. Las industrias culturales son también una de las formas que adquiere el folclor. En la ciudad también 
existen proyectos que le apuestan a la diversificación y mercadeo de este tipo de danza. Dicho sea de paso, estas organizaciones se encuentran inscritas como empresas en el sector y suelen diversificar su oferta e interactuar con otros géneros dancísticos como el ballet, la danza afro, la danza árabe, urbana, entre otros. Las propuestas creativas en este contexto responden a figuras o códigos como las revistas musicales que atienden temas comerciales, así como ritmos modernos y latinos que se han convertido en una mezcla entre la formación de academia y los productos vendibles a nivel internacional.

\section{Procesos, estrategias y aportes de las políticas culturales locales}

En Colombia la cultura cuenta con una legislación que es el respaldo político y estratégico para su desarrollo. Sin embargo, en la mayoría de los territorios existe poco diálogo y reconocimiento de la realidad de las organizaciones que agencian las prácticas artísticas. A nivel nacional, la política de cultura para la danza recoge la necesidad de ampliar la base social del arte y resalta la importancia de fortalecer las organizaciones y agentes del sector. Además, es preciso incluir acciones de capacitación orientadas a los formadores, intérpretes, creadores, productores, gestores, así como dar un énfasis particular a los públicos que se han visto enormemente afectados por consignas de gratuidad derivadas de la falta de reconocimiento por la labor artística.

En Medellín, hacia el año 2002, se produjo la estructuración de la Secretaría de Cultura Ciudadana bajo el Decreto 151, con el propósito de transformar la cultura ciudadana y ampliar el horizonte de las políticas culturales de la ciudad a partir de la concepción y práctica de los derechos culturales. Particularmente, los planes de desarrollo de la ciudad, tales como "Medellín competitiva, hacia una revolución de la cultura ciudadana" (2001-2003), "Medellín, compromiso de toda la ciudadanía" (2004-2007), "Medellín es solidaria y competitiva" (2008-2011) y "Medellín, todos por la vida" (2012-2015) constituyen un eje de continuidad en el proyecto de la ciudad que ha hecho de la cultura ciudadana el eje de su transformación. Y en el Plan de Desarrollo Cultural a 2020 se reafirma: Medellín, una ciudad que se piensa y se construye desde la cultura. Este proyecto se encuentra como Acuerdo Municipal del 2015. Está fundamentado en procesos de participación sectorial, intersectorial, poblacional y territorial. Además, reafirma el papel central de esta instancia en las políticas de gobierno y en la construcción de gobernanza y gobernabilidad local mediante un ejercicio que consolida el Sistema Municipal de Cultura como un recurso gubernamental para la construcción de ciudadanía democrática cultural.

En el Plan Sectorial proyectado para el 2020 se asume la cultura como factor de competitividad que está respaldado por la Alcaldía municipal bajo la apuesta 
denominada "Medellín Creativa". La finalidad de esta apuesta es mapear e identificar las actividades y la participación de la industria de lo creativo en la ciudad siguiendo las pautas de la planeación estratégica. En esta labor se halla una mirada de lo cultural asociada al desarrollo económico y productivo, cuyo elemento diferenciador es la economía basada en la auto sostenibilidad. Adicional a ello, la preocupación por el tema de una política pública para la danza ha llevado a consolidar una alianza con la academia con la que se está construyendo actualmente un estado del arte desde una perspectiva institucional que permita aportar estrategias que fortalezcan el sector.

Son estos discursos los que soportan la cultura desde múltiples niveles (nacional, regional, local) con miradas algunas veces integradoras, y otras, segmentarias. Estas miradas se sustentan en discursos incluyentes frente al encuentro ciudadano y la participación comunitaria que se entremezclan con conceptos de industrias creativas, sostenibles y económicamente rentables. Todos estos elementos confluyen en la formulación de planes intersectoriales para impulsar ecosistemas creativos en un marco de actuación orientado, al menos en teoría, hacia la cultura ligada al desarrollo de tipo economicista y, principalmente, a la creación de cadenas de valor que impacten los mercados nacionales e internacionales.

\section{Danza: planeación y territorio}

La planeación ha sido uno de los instrumentos que mayor despliegue ha tenido durante las últimas décadas. Por esta razón no solo se planea el ordenamiento de las ciudades y países, sino de los procesos que requieren estructurarse para viabilizar los recursos de acuerdo con las demandas de los ciudadanos. El ciudadano-artista es también objeto de estas prácticas y los entes que gobiernan sobre los diferentes niveles territoriales son los que determinan y construyen planes de acción que viabilizan estas labores. De esta manera, al Ministerio de Cultura de Colombia le corresponde regular los macroprocesos relacionados con la cultura dancística del país.

Una de las acciones que se plantean en este nivel contempla la información con respecto al número de organizaciones o agrupaciones de danza que actualmente existen en el país, la caracterización de las actividades y géneros que desarrollan y su ubicación. Esta apuesta responde a la necesidad de sistematizar los registros obtenidos en los diálogos de danza para consolidar la información de cada departamento y región con miras a establecer las necesidades comunes del área de danza en cada uno de sus componentes y brindar información respecto al fomento de la danza que se desarrolla desde otras instancias en el país, como los circuitos existentes, los procesos de formación en los diferentes niveles, las experiencias significativas, los estímulos, los procesos organizativos, etc. 
Para abordar el tema particular de la danza, el Ministerio de Cultura acude a formas de clasificación, tales como la danza tradicional, la danza folclórica, la danza contemporánea, la danza clásica, la danza moderna, los bailes de salón, la danza integrada (que designa la expresión de la población en situación de discapacidad), el ritual de los pueblos indígenas, el baile deportivo, las danzas urbanas de gran valor para la juventud y la danza teatro. Todas estas expresiones soportan y constituyen las identidades, lo nacional, lo popular, lo juvenil, lo urbano en una permanente dinámica.

En consecuencia, la mirada nacional evidencia el problema que consiste en querer establecer políticas culturales orientadas desde esta diferenciación que prioriza la forma en un país que presenta vivencias corporales desde la cotidianidad, el oficio y el conocimiento profesional. Esto se vuelve sumamente complejo. Por ello, se acude a establecer pequeños nodos en la búsqueda de aspectos en común que serían el hacer mismo de la danza (la expresión de la danza), cuyo objeto es la preservación de su memoria, la interrelación de sus lenguajes y la proyección de su diversidad.

En el tema de sostenibilidad, la mirada del Estado considera aspectos como las intervenciones urbanas que procuran la igualdad de los ciudadanos, el uso del espacio público para el encuentro ciudadano, la participación comunitaria y el acceso a la cultura a través de una amplia oferta de programas y proyectos en los ámbitos de la ciudadanía cultural, las bibliotecas, los centros de documentación, los archivo históricos, el patrimonio, las memorias, las lecturas, las escrituras y las manifestaciones artísticas y culturales en general.

Para el ámbito departamental y local, la ausencia de investigaciones relacionadas con las necesidades y realidades del sector de la danza se convierte en un impedimento para el fortalecimiento del sector. A pesar de los esfuerzos que se han realizado para establecer los planes en ambos niveles, la información allí consignada aún es abstracta y generalizada. Además, los canales de comunicación son escasos, muchas de las bases de datos no están actualizadas o no existe acceso a la información, lo cual limita la participación y, por ende, la formulación de políticas efectivas e impactantes como las que el sector dancístico requiere.

En lo que respecta al ámbito presupuestal, la modalidad de fondos, bolsas concursables y convocatorias son una manera de garantizar la participación y el acceso a los recursos para cultura desde el orden nacional, departamental y municipal. En esta se privilegia el apoyo del Estado hacia resultados inmediatos y visibles y no hacia los procesos a mediano y largo plazo. Sumado a lo anterior, la poca inversión para la cultura ha obligado a las organizaciones a asumir el tema de la sostenibilidad a través de labores de voluntariado. 
Así las cosas, el acceso a los recursos del Estado se hace mediante la participación en estos mecanismos que generalmente incitan a la competencia entre las organizaciones del sector de la danza, o conducen a la exclusión de organizaciones por falta de capacidad instalada, por poca cualificación en gestión de proyectos o por falta de experiencia.

En la revisión realizada para elaborar este texto, es clara la necesidad de fortalecer el sector de la danza a partir del reconocimiento de su diversidad y de la necesidad de impulsar su autonomía. Es menester prestar gran atención a las condiciones políticas y sociales que se requieren para garantizar el desarrollo del sector, mejorar las capacidades de gestión y la calidad de las propuestas artísticas. Asimismo, se busca impulsar el desarrollo sostenible de la práctica de la danza en el marco de las economías creativas que generen cadenas de valor, riqueza social y económica para el país.

Ante la pregunta por la forma en que las políticas han impactado la sostenibilidad de los grupos, la mayoría de líderes y maestros consideran que estas propuestas son escasas y no todos tienen el privilegio de acceder a ellas, ya sea por desconocimiento o poca apropiación frente a los pasos a seguir. Sin embargo, se reconoce que han fortalecido procesos creativos, administrativos, educativos o formativos en el campo de lo cultural. Para Camilo Maldonado, las políticas culturales tienen un impacto eventualmente positivo en algunas agrupaciones, pero también hay consecuencias negativas, ya que muchos grupos lo ven como la única base de su sostenibilidad. Adicional a ello, estas políticas:

[...] se van heredando de una administración a otra, se van modificando parcialmente, pero son políticas que no obedecen a una visión, no son políticas que tengan una claridad acerca de hacia donde se quiere ir con la danza, en nuestro caso, por eso la importancia de tener un plan municipal de danza y políticas culturales claras (...) y la política pública en general debe abarcar a todos los actores; tanto artistas, como espectadores, como administración municipal y como empresa, mientras la empresa no esté involucrada en la oferta y demanda, pues difícilmente van a apoyar positivamente al sector cultural, porque ahí, hay un vacío en esa cadena. (Maldonado, comunicación personal, 9 de noviembre de 2018)

En síntesis, los recursos siguen siendo limitados para el caso de los grupos independientes de danza folclórica que aplican a recursos públicos o que indirectamente se benefician de estas políticas. Tampoco aseguran la permanencia en el tiempo ya que son inversiones ligadas a eventos, celebraciones de ciudad y en pocas ocasiones se destinan al fortalecimiento de las otras dinámicas que permitan lo que aquí se ha denominado sostenibilidad integral. 


\section{La sostenibilidad desde el "hacer": una lectura necesaria}

Este eje reflexivo se realizó mediante el levantamiento de información a través de una cartografía en la cual participaron 11 de las 22 entidades que pertenecen a la Red Arcalía. El ejercicio se dividió en tres momentos. En el primer momento reflexivo se sensibilizó a los actores con respecto a las posibles miradas de la sostenibilidad y se les motivó a participar y registrar la realidad que efectivamente acontece en sus grupos. El segundo momento tuvo que ver con la ubicación de las acciones en el territorio de acuerdo con los componentes como lugares de ensayo, oficina, bodega, espacios donde se desarrollan funciones de proyección, participación social, aliados que apoyan el trabajo, relación con organizaciones de enfoque comunitario, existencia de correo, redes sociales, página web, relación con organizaciones de enfoque social, vínculos con entidades públicas, vínculos con entidades privadas, nodos (participación en red), participación en convocatorias, recursos propios, capital del grupo y egresos. Finalmente, en el tercer momento se hizo la socialización y escucha de las propuestas. También se hizo la ubicación de las elaboraciones gráficas en el mapa de Medellín con el fin de observar el impacto de la práctica artística folclórica de los grupos independientes a nivel territorial.

Se definieron cinco categorías para la reflexión, que se ilustran en la figura 1.

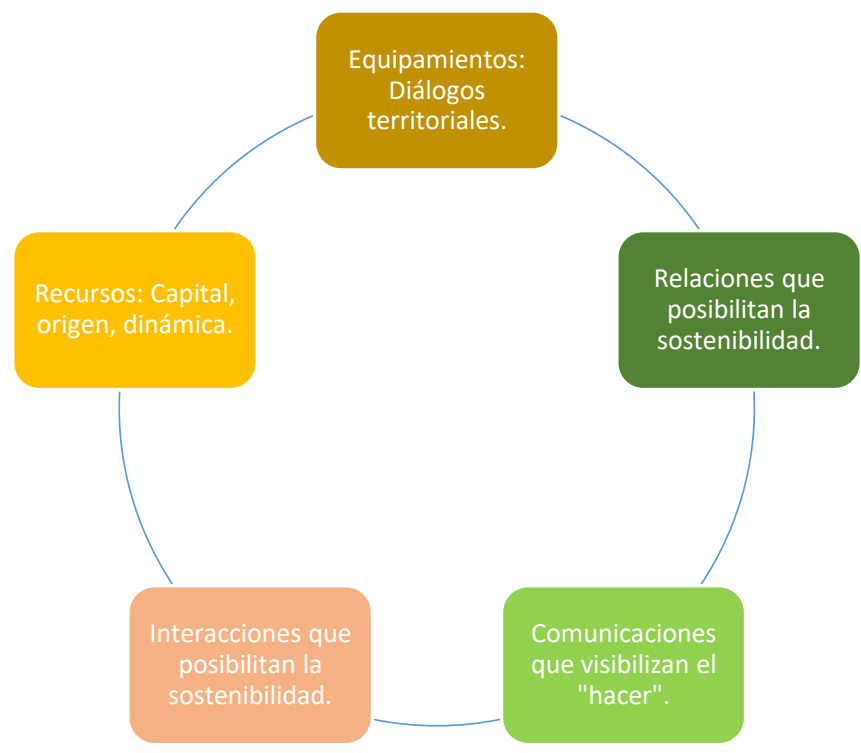

Figura 1. Sistema de categorías para el mapeo de la sostenibilidad Fuente: elaboración propia. 


\section{Hallazgos}

\section{Equipamientos: Diálogos territoriales}

Para espacios de ensayo los grupos independientes utilizan diversidad de sedes, tales como:

- $\quad$ Sede propia: 2

- JAC: 2

- Instituciones educativas: 1

- Equipamientos de la Alcaldía (UVA): 3

- Otras sedes culturales: 1

- Otros espacios: 2

- No especifican: 2

Se observa que los grupos, aunque ejercen sus labores artísticas en comunas definidas, deben sortear las dificultades de espacio, bodega y oficina desplazándose hacia otros sectores, por lo que se puede pensar que su rango de acción se expande y vincula otros territorios, ya que los componentes de gestión deben ser desarrollados en sitios diferentes a los de ensayo o labores artísticas. Incluso, en algunos casos se utilizan espacios de otros municipios del área metropolitana, tales como casas de integrantes de los grupos o de los mismos directores, como bodega, oficina, etc. Al respecto se observa la siguiente interacción con otros territorios:

- $\quad$ Sin fronteras: comunas 5 y 7

- Fantasía Guayaquil: comunas 11 y 9

- Guateque: comunas 12 y Envigado

- Matices: comunas 4 y 5

Con respecto al uso de espacios como oficina, 5 grupos no especifican, 1 refiere tener archivo, 2 cuentan con salas de reuniones, 1 indica que es el mismo lugar de ensayo y 2 manifiestan que este espacio es la casa de los directores. Solo uno indica tener insumo como computador por comodato. Las bodegas o lugares para acopiar y proteger los elementos necesarios para la danza son mínimos y se encuentran dispersos en muchos casos. Se distribuyen de esta manera:

- Bodega: 2

- Espacio asignado en el mismo lugar de ensayo: 3

- Otros espacios: 1 
- Casa de fundadores, directores u otros miembros del grupo: 3

- Espacios en alquiler: 1

- No especifican: 2

Con respecto a los lugares en los que se realizan las funciones se mencionan los siguientes:

- Sedes de danza Canchimalos y Casa Danza

- Sedes teatrales Lido y Fanfarria

- Juntas de acción comunal

- Uvas

- Municipios de Antioquia

- Casas de la Cultura

- Centros Comerciales Monterrey, San Diego y Unicentro

- Espacios dispuestos por eventos locales como Folcloriada y Ruta de ciudad

- Espacios dispuestos por eventos internacionales (México, Argentina, Chile)

- Entidades privadas

- Instituciones educativas, universidades y sus sedes

Finalmente, con respecto a los espacios el mapeo permitió observar una mayor concentración de las actividades de los grupos en las comunas 12 y 13, seguidas de las comunas 4 y 5 y las comunas 11 y 7 . Esto se debe a asuntos como la priorización de recursos por presupuesto participativo, una mayor fortaleza en su infraestructura organizativa, una mayor permanencia en el tiempo de los grupos existentes y la respuesta de resistencia desde la cultura a fenómenos de disputa por el control territorial en ciertas zonas de la ciudad.

\section{Relaciones que posibilitan la sostenibilidad}

Dentro de estas relaciones se cuestionó la participación, los aliados y las relaciones de tipo comunitario. Al respecto cabe aclarar que el número de grupos abordados fue de 11 y que el número que aparece al lado derecho de cada denominación se refiere al número de respuestas obtenidas; en este caso los grupos mencionaron su participación en las siguientes instancias:

- Consejo de cultura: 2

- No especifica: 2

- Comisión de cultura: 1 
- Presupuesto participativo: 2

- Consejo de danza: 2

- Subsector adulto mayor: 1

- Mesa de cultura:1

- Junta de acción comunal: 2

- Otros:1

Por otra parte, frente a quienes consideran aliados relevantes para su sostenibilidad y desarrollo de actividades, los participantes indicaron:

- Instituciones educativas: 2

- Transporte (personas naturales): 1

- Asesores profesionales (personas naturales): 2

- Operadores logísticos de corredores artísticos en las comunas: 1

- Juntas de acción comunal: 3

- Personas y empresas de vestuario: 3

- Maestros del folclor: 3

- Otros grupos de danza: 1

- Organizaciones comunitarias: 2

- Líderes sociales: 1

- Comercio del barrio: 1

- Alcaldía: 1

- Red Arcalía: 2

- Otros países: 2

- Padres de familia: 1

- UVA: 1

- Corporaciones: 1

Por último, con respecto a las organizaciones de tipo comunitario con las cuales se relacionan, se observa que son escasas. 5 grupos no manifestaron tener este tipo de vínculos. Otros mencionaron que tienen vínculos con las sedes sociales, clubes de vida, vecinos y barrios de la comuna en general. 


\section{Comunicaciones que visibilizan el "hacer"}

Las comunicaciones se entendieron como una plataforma visible de las agrupaciones que han empezado a diseñar estos espacios para favorecer las evidencias de su trabajo, montajes, propuestas, etc. Por lo tanto, se consideraron aquí los correos electrónicos del colectivo y las redes sociales utilizadas en las labores de gestión y proyección

Todas las agrupaciones cuentan con correo electrónico. Con respecto a redes sociales solo una de ellas manifiesta que no tiene. Las demás cuentan con:

- Facebook: 5

- Twitter: 1

- Canal de youtube: 1

- Instagram: 1

- Whatsapp: 2

- Tienen redes, pero no especifican cuáles: 3

Finalmente, la página web también es un recurso utilizado por algunas de ellas: siete manifestaron tenerla habilitada y actualizada, mientras que cuatro no mencionaron o especificaron si cuentan con ella.

\section{Interacciones que posibilitan la sostenibilidad}

En la categoría "interacciones" se agruparon aquellos componentes que posibilitan la sostenibilidad pensada desde un enfoque que va más allá de lo financiero. Por lo tanto, se incluyeron las relaciones de doble vía que se establecen con organizaciones, entidades públicas y privadas y esfuerzos implementados para el trabajo en red.

Seis agrupaciones manifestaron que no tienen relaciones con otras organizaciones de este tipo. Llama la atención una cifra como esta, ya que tampoco se evidencia en las organizaciones mencionadas algún vínculo internacional o alianzas que faciliten y contribuyan a la gestión de recursos. Dentro de las organizaciones sociales que contribuyen a la sostenibilidad de los grupos a través del intercambio están:

- Faong

- Metropolitano

- Sol y luz

- Picacho con Futuro 
- Convivamos

- Corporaciones culturales

- Cojar

- Madres comunitarias

- Iglesia

Por su parte, las entidades públicas con las cuales más se relacionan los grupos son:

- Alcaldía de Medellín (Secretarías de cultura, educación, participación): 8

- Metroparques: 1

- Facultad de Artes de la Universidad de Antioquia: 1

- Programa de presupuesto participativo: 2

- Inder: 1

- Universidad de Antioquia: 2

- Velódromo: 1

- Ministerio de Cultura: 1

- Gobernación de Antioquia: 1

- Municipios de Antioquia: 1

Con respecto a entidades privadas se mencionaron las siguientes:

- Universidades (practicantes, visitas pedagógicas): Eafit, Universidad de Antioquia

- Confiar cooperativa

- Comfenalco

- Centros comerciales San Diego y Monterrey

- Kamado showmaker

- Vía Libre

- Casa danza

- Hospital (No indican cuál)

- Medicáncer

- Colegios privados 
El trabajo en red aparece como otro de los componentes diversos para los grupos. Además de Arcalía, se mencionó la participación en:

- Red Cultual Expresarte (Comuna 13)

- Red de Medios Cultura Viva Comunitaria

- Articulaos

- Medellín en Escena

- Plataforma Puente

- Potro Azul

- Espiral Creativa

- Red de Danza Folclórica por pareja

- Red de Adulto Mayor

- Red de Grupos Independientes Infantiles

- Cultura Belén

Ahora bien, no se especificó la calidad de las participaciones, más allá de integrarlas ni cuáles han sido los beneficios de estas alianzas. Este aspecto requiere un mayor dinamismo y medición.

\section{Recursos: capital, origen, dinámica}

Estos tres aspectos definen buena parte de la sostenibilidad económica de los grupos, razón por la cual las preguntas se centraron en reconocer que el voluntariado, la donación, y el capital humano son relevantes como componentes de la sostenibilidad. Los medios por los cuales se obtienen recursos son:

- Contratos: 1

- Convenios: 1

- Venta de espectáculos artísticos (funciones pagas): 6

- Alianzas: 1

- Voluntariado de los participantes: 4

- Mensualidad de clases: 1

- Proyectos: 1

- Estímulos: 1 
- $\quad$ Becas: 1

- Donaciones: 4

Con respecto al capital, se tuvieron en cuenta los recursos propios y acumulados en el tiempo. La mayoría de las adquisiciones corresponden efectivamente a las necesidades materiales para el desarrollo de los procesos artísticos. Por ello, se reconocen los vestuarios y en pocos casos luces y escenografía, sobre todo en los grupos que cuentan con sala de danza, así como con dotación propia de sus salas. Otras propiedades relevantes que se mencionaron fueron:

- Archivo documental: Canchimalos

- Escuela de artes integradas: Canchimalos

- Seminarios formativos y encuentros: Canchimalos

- Producciones musicales: Canchimalos

- Obras: Todos

- Producción bibliográfica: Canchimalos

- Informes de investigación: Canchimalos, Guateque

- Transporte de integrantes

- Experiencia de los bailarines de cada área

- Uniformes

Finalmente, con respecto a los egresos se mencionó una multitud de situaciones relacionadas con ellos:

- Proyectos (pago a docentes y materiales): 1

- Transporte: 5

- Refrigerios: 4

- $\quad$ Servicios públicos: 3

- Confección y mantenimiento de vestuarios: 5

- Pago de honorarios a personal administrativo: 2

- Deudas: 5

- Pago a bailarines: 1

- Pago por recursos técnicos para obras: 1

- Pago músicos: 1

- Escenografía: 1 
- Pago a directores (honorarios, salud): 2

- Pago por movimientos bancarios: 1

- Formación: 1

- Alquiler de bodega para vestuario: 1

\section{Conclusiones}

De acuerdo con lo expuesto, cabría preguntarse entonces por la actual perspectiva de los grupos y por las vías necesarias para la identificación de los comunes arraigados en las ciudadanías "otras", las que se hacen en los colectivos y que se cuestiona por las maneras en que se entiende y funciona- la cultura; en un sentido que hace eco de las reflexiones propuestas por Rowan (2016) cuando propone la pregunta: "¿Tiene sentido pensar en una cultura libre del Estado?" (p. 12).

En este caso específico y bajo los parámetros que definen el "hacer" danza en la ciudad, también es importante pensar si efectivamente se ha avanzado de manera inconsciente hacia una construcción de una "sostenibilidad insostenible" a largo plazo de la mano de las políticas diseñadas durante los últimos años, ya que no se ha logrado un empoderamiento ciudadano que trascienda las lógicas participativas institucionales para responder a principios éticos de solidaridad y trabajo del sector.

Aún hay mucho que explorar en los modelos de gestión existentes, en los diálogos logrados con los discursos de innovación y el emprendimiento cultural, los cuales en lugar de impulsar un agenciamiento de los grupos culturales independientes, suelen conducir a procesos de corto o mediano aliento en los que las capacitaciones y los talleres son la base y se desdibuja el direccionamiento de las relaciones, alianzas o trabajo intersectorial. De esta manera, se fomentan las lógicas de competencia propias de la supervivencia en un medio que a menudo carece de ética, el mantenimiento de las sedes y proyectos artísticos por unos cuantos líderes y la perpetuación de las rivalidades que históricamente se han dado como parte de la creación a nivel local.

Por otro lado, en una paradoja permanente, las agrupaciones independientes que se han mantenido lo hacen unidos a la definición de proyectos de vida ligados a la danza por parte de los directores que se convierten en militantes de la labor artística y se ven abocados a invertir más de lo esperado, a apoyarse en sus círculos sociales cercanos mediante favores, prestamos o voluntariados que terminan por sobrecargar, desmotivar y debilitar a los líderes artísticos. 
Si bien lo económico es una dificultad substancial y constante para los grupos que, además, dificulta procesos como la planeación, el trabajo en red, la integración de saberes y el trabajo solidario, son muchas las amenazas de la labor artística para cualquier grupo independiente de la ciudad. En la mayoría de los casos tampoco se cuenta con el cubrimiento de asuntos como la seguridad. El artista mismo es quien debe gestionar su salud, capacitaciones, transporte, alimentación, sin contar los materiales y elementos de la producción escénica.

Además, poco se ha pensado o avanzado en la consideración de la propiedad intelectual. Cuando se presentan las obras en concursos y becas no se tienen claridades específicas al respecto, por lo que se constituyen potencialmente como un "dispositivo de desposesión de sus ideas" (Rowan, 2016, p. 13). Hace falta entonces mayor consciencia frente a las formas en las que el artista proyecta su trabajo, lo postula o lo circula, de manera que estas acciones no generen precariedad en la valoración y dignificación del quehacer artístico a nivel local.

Por otra parte, podría decirse que la oferta formativa para los artistas de la danza folclórica en Medellín se ha agotado en la transmisión de las "formas" de enseñar o transmitir su saber - cosa que ya venían haciendo sin la necesidad de que la academia validara sus conocimientos- y poco se ha ahondado en la generación de una capacidad instalada que responda a las necesidades reales del sector en cuanto a: dinámicas del mercado, importancia de la participación política no solo institucional sino legítima (gremios, asociaciones, redes, etc.), valoración de su producción con relación al patrimonio intangible de la ciudad, procesos investigativos y de circulación del conocimiento y acervo logrado por los grupos, entre otros.

Existe entonces una carencia de espacios de diálogo. Los pocos encuentros que se realizan son dedicados principalmente a la planeación de actividades de ciudad (espectáculos, festivales) y no precisamente a una articulación que permita a todos los grupos avanzar como colectivos pertenecientes a una red que funcione como tal. Además, convendría realizar estos diálogos , los en varios niveles, de tal forma que se interactúe con mayor fuerza con sectores como los entes gubernamentales, la academia, lo social-comunitario, lo ambiental, entre otros.

De acuerdo con Rowan (2016), "no hay transformación económica sin transformación social" (p. 18). Esto implica que los primeros cambios necesarios a la hora de hablar de una mirada crítica a la sostenibilidad provienen del tipo de relaciones, deseo y necesidades que definen el ámbito de la danza folclórica en la ciudad. Es más, es necesario que se tenga en cuenta que la premisa de permanencia de estos grupos posee un trasfondo de conservación de las tradiciones -que también se entienden como dinámicas- generación tras generación. 
Es por ello que es indispensable empezar a trabajar al nivel de modelos organizativos y productivos que no solo mejoren la calidad de vida de los danzantes, sino que permitan escenarios de co-creación y de co-gestión en los cuales el trabajo en red sea posible y los participantes y grupos se beneficien a desde sus múltiples realidades. Indiscutiblemente, también se hace necesario pensar en los públicos, no solo en el plano formativo, sino en las narrativas que ellos demandan, las formas de convocatoria y el establecimiento de un consumo responsable que reconozca en la práctica folclórica una fuente de la riqueza cultural de la ciudad, la región y el país.

\section{Agradecimientos}

Este artículo deriva del proyecto ganador de la Convocatoria de Estímulos para el Arte y la Cultura 2018 de la Alcaldía de Medellín, en la modalidad de Beca para la elaboración de ensayos de crítica en audiovisuales, danza, música, teatro, artes visuales y gestión cultural. Se agradece a la Red de Grupos de Danza Folclórica Independientes Arcalía y a la licenciada Lina Margarita Rojas Lopera.

\section{Referencias}

Anastasopoulos, N. (2017). Buen Vivir, sostenibilidad y bienes comunes: el contexto ecuatoriano y mundial. Estado \& comunes, 1(4), pp. 39-55

Ángel, S. (2010). Lineamientos del Plan Nacional de Danza para un país que baila 2010-2020. Bogotá, Colombia: Ministerio de Cultura. Recuperado de: https://www.mincultura.gov.co/areas/artes/ danza/Documents/LineamientosPlanDanza2aEdicion.pdf

Arcalía Red Sector de Danza Folclórica de Medellín y Valle De Aburrá. (2016). Estado del arte de los grupos independientes y universitarios de danza folclórica de Medellín. Medellín, Colombia: Ministerio de Cultura.

Castrillón, J. (2015). Reflexiones sobre la sostenibilidad integral de los procesos de Cultura Viva Comunitaria. Ponencia presentada en el IV Foro Cultura Viva Comunitaria en Clave de Futuro, Medellín, Colombia

Rowan, J. (2016). Cultura libre de Estado. Madrid, España: Traficantes de Sueños. Recuperado de: https://www.traficantes.net/sites/default/files/pdfs/LEM7_cultura\%20libre\%20de\%20Estado.pdf 